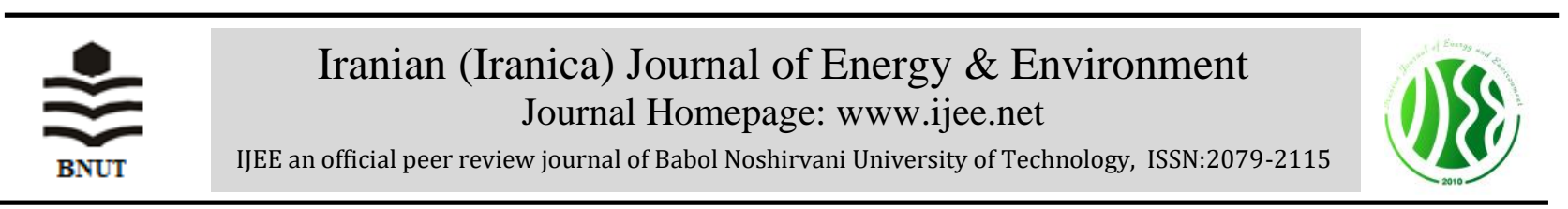

\title{
Utilization of Soil Temperature Modeling to Check the Possibility of Earth-Air Heat Exchanger for Agricultural Building
}

\author{
H. Faridi ${ }^{1}$, A. Arabhosseini' ${ }^{*}$, G. Zarei ${ }^{2}$, M. Okos $^{3}$ \\ 1 Department of Biosystems Engineering, College of Aburaihan, University of Tehran, Tehran, Iran \\ ${ }^{2}$ Agricultural Engineering Research Institute (AERI), Agricultural Research, Education and Extension Organization (AREEO), Karaj, Iran \\ ${ }^{3}$ Department of Agricultural \& Biological Engineering, Purdue University, West Lafayette, USA
}

\section{$P A P E R \quad I N F O$}

\section{Paper history:}

Received 29 September 2019

Accepted in revised form 24 November 2019

\section{Keywords:}

Energy Saving

Passive

Renewable Energy

Shallow Geothermal

\section{$A \begin{array}{llllllll} & S & T & R & A & C & T\end{array}$}

The commonly used energy in Iranian greenhouses is provided from gas or diesel fuel. As fossil fuels will be finished in the coming years, the utilization of renewable energies could be quite significant. In this research, the thermal potential of the soil profile was studied in Kouhsar, Alborz province, Iran, for utilizing the shallow geothermal energy in order to supply thermal demands of building like greenhouses. Therefore, the temperature sensors were set at the four depths of $30,100,200$, and $300 \mathrm{~cm}$ as well as at the ground surface. The results showed that the greater the depth, the less fluctuation of the soil temperature as well as the greater the temperature difference of the soil profile against the ambient air temperature. These results suggest that the potential of the earth could be used to warm up or cool down in this location for an agricultural structure like greenhouse. The soil profile temperature behavior was modeled at different depths by two methods as heat transfer and empirical. The empirical model was simpler than the other one. As the possibility of using geothermal energy in this region has not been investigated. This research could be an effective step for using renewable energy for agricultural structures like greenhouses.

doi: $10.5829 /$ ijee.2019.10.04.06

\section{INTRODUCTION}

For many years, human beings have been thinking for developing appropriate technologies to improve their life and meet their needs. Energy plays an important role in the development of human sciences, since all processes undergo energy and energy conversion to other types. In this regard, fossil fuels play an important role but, the end-use of energy from fossil fuels, especially crude, the today's world requires using other resources to replace it [1]. Recently, in addition to the food and water crises in the world, the energy crisis is also quite noticeable [2].

Today's human life depends directly and indirectly on various sources of energy such as oil, gas and so on, and it is hard and even impossible to imagine living without access to these resources. On the other hand, the rapid passage of time makes this alarm taller and obvious that non-renewable energy sources are ending, so the need to discover and use new energy sources is becoming more and more serious [3]. As a result, solutions that can be used economically from clean energy are considered $[1,4]$.

Following the recommendation for using clean or renewable energies, in recent years, the use of solar energy has been a source of great interest, but the great problems is the non-economics and the limitation of its use when it comes to cloudy sky or night. Other sources, such as the use of marine energy, etc., are expensive because of their high initial cost and the need for high technology, as well as being located in a specific position near the sea, which there is little use in energy supply. This makes these mentioned sources of renewable energy impossible to use everywhere [5-8].

Among renewable energies, geothermal energy is not depended on the season, time, and conditions and also can be non-stop operation [9-11]. In principle, the temperature below the soil surface remains almost constant during the year from a certain depth to the next, which is known as the "Earth's Undisturbed Temperature (EUT)."This rule is based on that as the depth increases, the amplitude of thermal variation decreases in comparison with the variation on the soil surface due to the soil thermal inertia. So in winter and summer, it can be used because in the winter the air in the depths of the earth is warmer than ambient air and vice versa in the summer [1213]. As a result, it can be used to warm or cool the air in the depths of the earth and transfer it to the soil surface in residential buildings, greenhouses, livestock and poultry units, etc. 
The earth-to-air heat exchanger systems (EAHEs) provide the potential for exploitation of stored energy from solar radiation at near-ground depths with a relatively low cost [1, 14-17]. It is actually the definition of shallow geothermal energy. These systems use the thermal energy of the soil below the ground as a permanent and constant source of energy. The soil profile temperature is higher in the cold season and lower in the warm season than the ambient air temperature. In practical terms, thermal energy reservoirs as geothermal resources can be exploited at costs competitive with other energy forms and are classified due to their reservoir fluid temperatures into low, medium and highenthalpy fields. Heat from the Earth's core cannot impress on the very shallow geothermal energy (about the first 10 meters below the soil surface) rather than by solar energy as the main one [18].

Several studies have been down on the application of ground-to-air heat exchangers, in particular, the study of the potential of using EAHEs and finding the appropriate depth for embedding [19-21]. Gouda [22] studied the application of geothermal energy for heating and cooling of agricultural structures in Egypt. Geothermal energy system was analyzed and restructured as three sub models including soil temperature model, EAHE model, and greenhouse model. This soil temperature model was more important than the others as it used as the main component of EAHE model. Another assessment of the thermal potential of EAHEs was experimentally performed by Vaz et al. [4] in the south of Brazil. They found that May and February were the best for heating and cooling the air used in this area, respectively. They also reported a complete database for the transient temperatures of the soil, external air and inside the building.

As soil temperature is a substantial parameter in geothermal energy applications such as the passive heating and cooling of buildings and agricultural greenhouses, most researchers, prior to placing the EAHEs in a desired depth, examine the potential of the area by different measurements of temperature fluctuates in different depths and develop different models as a utility to achieve better performance [24-26].

What is evident in the previous studies is that the modeling performed for the temperature of the soil at different depths was only solvable by the heat transfer equation, but along with this method, it is possible to use mathematical modeling that is easier to do and it also requires less parameters than the heat transfer equation as the initial and boundary conditions, among which are the most important parameters of the climate history of an area that may not be available or not sufficiently precise. Also, the solution of the heat transfer equation requires soil parameters that are time-consuming and costly tests. On the other hand, the assumptions used for simplicity in numerical simulation or solving the heat transfer equation may reduce the accuracy of calculations and estimate temperature at different depths.

Since the areas of Alborz province in Iran have many potentials for the development of greenhouses with the utilization of green energies and also the potential of the EAHE system is not surveyed in this zone while the energy crisis is felt more than before in Iran, this study was performed to evaluate the EAHE application to provide heating and cooling needs of a commercial greenhouse by asking this question "Is this region capable of using this energy? Or not". For this purpose, thermal process of the earth in terms of a database about the transient temperatures of the soil and the external air was presented with the help of two methods of modeling including heat transfer and empirical. If the climatic, geographic and soil characteristics of this area provide the potential for geothermal energy, it can be an important step in utilizing this renewable energy in agriculture, including greenhouse energy requirements as heating, cooling and also ventilation.

\section{MATERIALS AND METHODS}

\section{System set up}

In this research, a field was considered for tests in Kouhsar, located in Alborz province, Iran (latitude $51^{\circ} \mathrm{E}$ and longitude $35^{\circ} \mathrm{N}$, at altitude of $1300 \mathrm{~m}$ above sea level) during the period of 15th January to 1st September, 2018. Temperature of the soil profile was measured at four depths of 30,100, 200 and $300 \mathrm{~cm}$ using resistance thermometers sensors of PT-100 with the accuracy of $0.1^{\circ} \mathrm{C}$ connected to a displayer to show the temperature of soil at desired depth. After embedding sensors in the desired depth, they were carefully backfilled and tamped with moist soil. Figure 1 shows the experimental set up. In addition to measuring the temperature of the soil at the stated depths; the ambient air temperature was recorded by ST-171 Data logger (Figure 1) during the aforementioned period (with the accuracy of $0.1{ }^{\circ} \mathrm{C} / \%$ for both temperature and relative humidity).

\section{Model Development}

The soil temperature behavior was modeled at different depths according to the temperature of the soil surface (ambient air temperature). The modeling process included two methods. First one is an empirical model resulted by the process of temperature changes relative to time using the Least Square Regression technique for choosing the best prediction function of soil temperature behavior versus time by Matlab 2016. The second one is heat transfer model, presented by other researchers and validated for the desired position with the available data $[4,10,12-13]$.

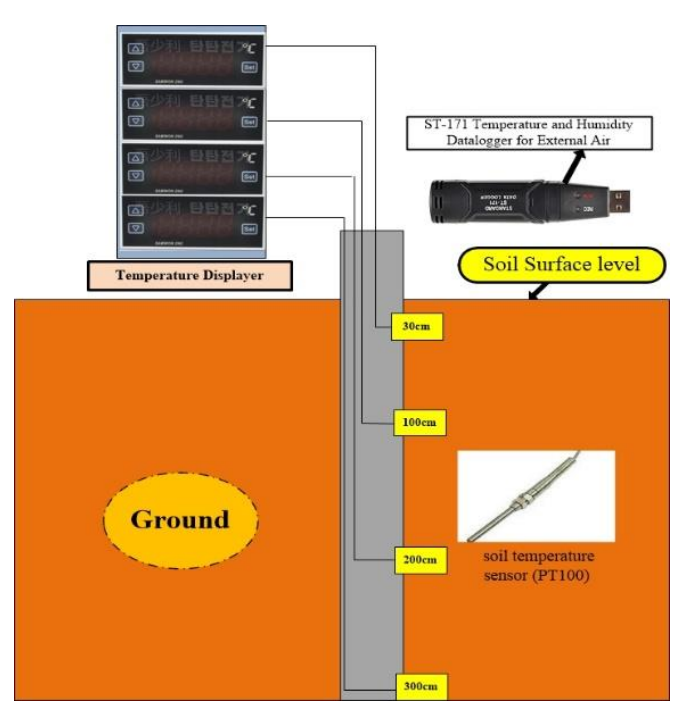

Figure 1. Schematic of measurement set up 


\section{Empirical model}

According to the measurements, the models based on periodic functions were evaluated by the least square regression techniques using curve fitting in MATLAB, version 2016. Among the several periodic functions, the sum of Sine, Fourier, and Gaussian functions was considered.

The obtained results from empirical models were evaluated and compared with each other by the R-Square, Root Mean Square Error (RMSE) and the Sum of Square Errors (SSE) statistics. Finally, the best descriptor of each empirical model was presented. However, the best descriptor empirical model was eventually compared with the heat transfer model.

The smaller the value of RMSE and SSE, the better is the model performance unlike the value of R-square. The RMSE and SSE statistics were computed as Equations (1) and (2) [18]:

$$
\begin{aligned}
& R M S E=\sqrt{\frac{1}{n} \sum_{i=1}^{n}\left(c_{i}-m_{i}\right)^{2}} \\
& S S E=\sum_{i=1}^{n}\left(c_{i}-m_{i}\right)^{2}
\end{aligned}
$$

\section{Heat transfer model}

For presenting a heat transfer model in this study, earth is assumed to be a semi-finite solid control volume (Figure 2). The general equation for heat transfer without considering the sun's radiation is as follows:

$$
\frac{\partial T}{\partial \mathrm{t}}=\frac{k_{s}}{\rho_{s} c_{s}}\left[\frac{\partial^{2} T}{\partial x^{2}}+\frac{\partial^{2} T}{\partial y^{2}}+\frac{\partial^{2} T}{\partial z^{2}}\right]
$$

To simplify Equation (3), given that the temperature of the earth no significant changes at a certain time along the surface relative to the lower depth, and then it can be assumed:

$$
\frac{\partial^{2} T}{\partial y^{2}}+\frac{\partial^{2} T}{\partial z^{2}}=0
$$

Therefore:

$$
\frac{\partial T}{\partial \mathrm{t}}=\frac{k_{s}}{\rho_{s} c_{s}}\left[\frac{\partial^{2} T}{\partial x^{2}}\right]=\alpha_{s} \frac{\partial^{2} T}{\partial z^{2}}
$$

where; $\alpha_{s}=\frac{k_{s}}{\rho_{s} c_{s}}$

Equation (5) can be solved concerning the boundary and initial conditions.

As the most important factor, the annual pattern of surface temperature can be described as a sine wave function of the average annual ambient air temperature [27]. The main amplitude of the surface temperature wave is dependent on the surface reflectivity and soil diffusion properties in the site. As the depth of the soil increases, the fluctuation decreases and the soil temperature becomes almost uniform. The temperature of the underlying layers of the soil numerically has been modeled based on the theory of heat transfer in a semi-finite solid body.

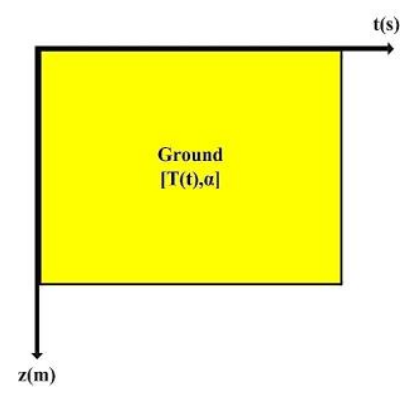

Figure 2. The earth model with the assumption of a semi-finite solid control volume
The temperature of the soil profile depends on some factors such as the depth and the time which are affecting on other parameters, such as the thermal permeability of the soil, which itself depends on the density, thermal conductivity, and specific soil radiance. Considering the solution of Equation (3) and assuming that the homogeneous soil has a constant thermal permeability, EUT at depth $\mathrm{z}$ and time $\mathrm{t}$ can be obtained from Equation (6) [29]:

$$
\begin{aligned}
& T_{(t, z)}=T_{\text {mean }}+A_{s} \exp \left[-z\left(\frac{\pi}{365 \alpha_{s}}\right)^{\frac{1}{2}}\right] \cos \left\{\frac{2 \pi}{365}[t-\right. \\
& \left.\left.t_{0}-\frac{z}{2}\left(\frac{365}{\pi \alpha_{s}}\right)^{\frac{1}{2}}\right]\right\}
\end{aligned}
$$

The following assumptions were considered as mentioned by Sharan and Jadhav [28] and ASHRAE [18]:

a) The soil surface temperature is equal to the air temperature

b) The lag phase is at the maximum air temperature

c) The annual amplitude of soil surface temperature is equal to the annual amplitude of air temperature.

$$
\begin{aligned}
& T_{(t, z)}=T_{m a}+A_{a} \exp \left[-z\left(\frac{\pi}{365 \alpha_{s}}\right)^{\frac{1}{2}}\right] \cos \left\{\frac { 2 \pi } { 3 6 5 } \left[t-t_{0}-\right.\right. \\
& \left.\left.\frac{z}{2}\left(\frac{365}{\pi \alpha_{s}}\right)^{\frac{1}{2}}\right]\right\}
\end{aligned}
$$

In this study, $T_{m a}, t_{0}$ and $A_{a}$ were taken as the average values of ten years from 2007 to 2017 weather data from Hashtgerd meteorological station in Alborz province, Iran, which is the closest station to the research zone. The soil thermal diffusivity $\left(\alpha_{\mathrm{s}}\right)$ in Equations (6) and (7) was calculated as follows [27]:

$$
\alpha_{s}=\frac{24 \times 3600 k_{s}}{1000 \rho_{s}\left[c_{s}+c_{w}(w / 100)\right]}=\frac{86.4 k_{s}}{\rho_{s}\left[c_{s}+4.18(w / 100)\right]}
$$

The thermal conductivity $\left(k_{s}\right)$ in Equation $(8)$ is calculated by the following empirical equation (Equation (9)) for unfrozen sandy soils [29]:

$$
k_{s}=(0.101 \log w+0.0577) 10^{0.000624 \rho_{\mathrm{s}}}
$$

The specific heat of dry soil $\left(c_{s}\right)$ in Equation (8) is nearly constant for all types of soil and equal to $0.73 \mathrm{~kJ} / \mathrm{kg} \cdot{ }^{\circ} \mathrm{C}$ as reported in ASHRAE [18].

\section{RESULTS AND DISCUSSIONS}

\section{Empirical models}

Based on temperature measurements at different depths of the soil with respect to time, several empirical models are presented using non-linear regression functions including the sum of Sine, Fourier, and Gaussian by Matlab Software based on the least squares method. According to Figures 3 and 4, and the results of the proposed models, the Fourier equation of binomial model (Fourier 2) is the best model for describing the thermal behavior of each soil depth in the desired time interval (January 15 to September 1, 2018) as it showed the least SSE and RMSE against the highest $\mathrm{R}^{2}$ for each desired soil depth. Table 1 shows a summary of the results of different empirical modeling.

In addition to the results of Table 1, as shown in Figures 3 and 4, it was observed that at a depth of $300 \mathrm{~cm}$, the difference between soil temperatures and air temperatures outside the soil was significant for both cold and hot days. From this, it can be concluded that as the depth increases, the temperature of the soil in the cold season is warmer than the air temperature outside the soil, and vice versa, in warm days, 

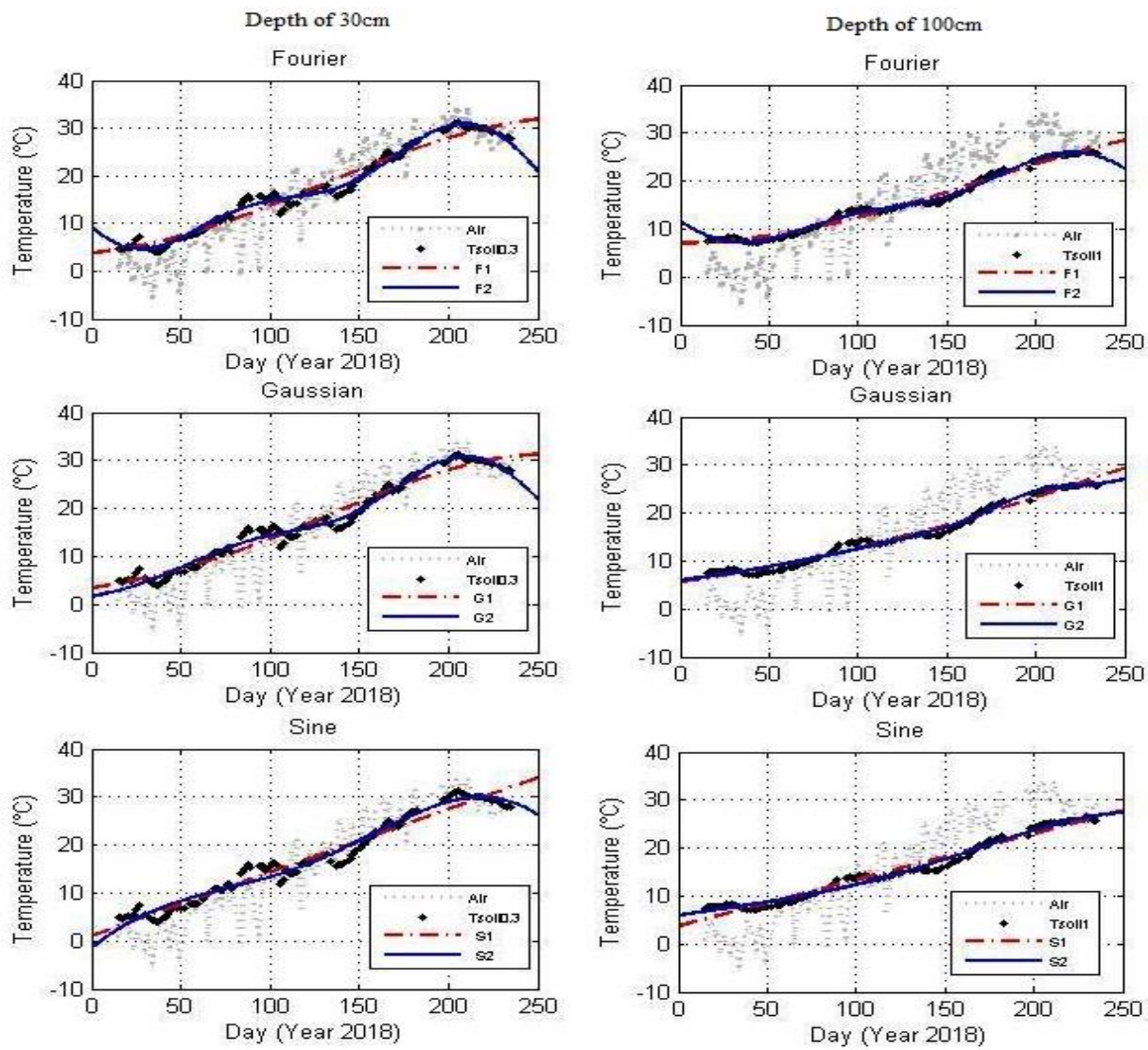

Figure 3. Empirical modeling of soil profile temperature fluctuation at the depths 30 and $100 \mathrm{~cm}$
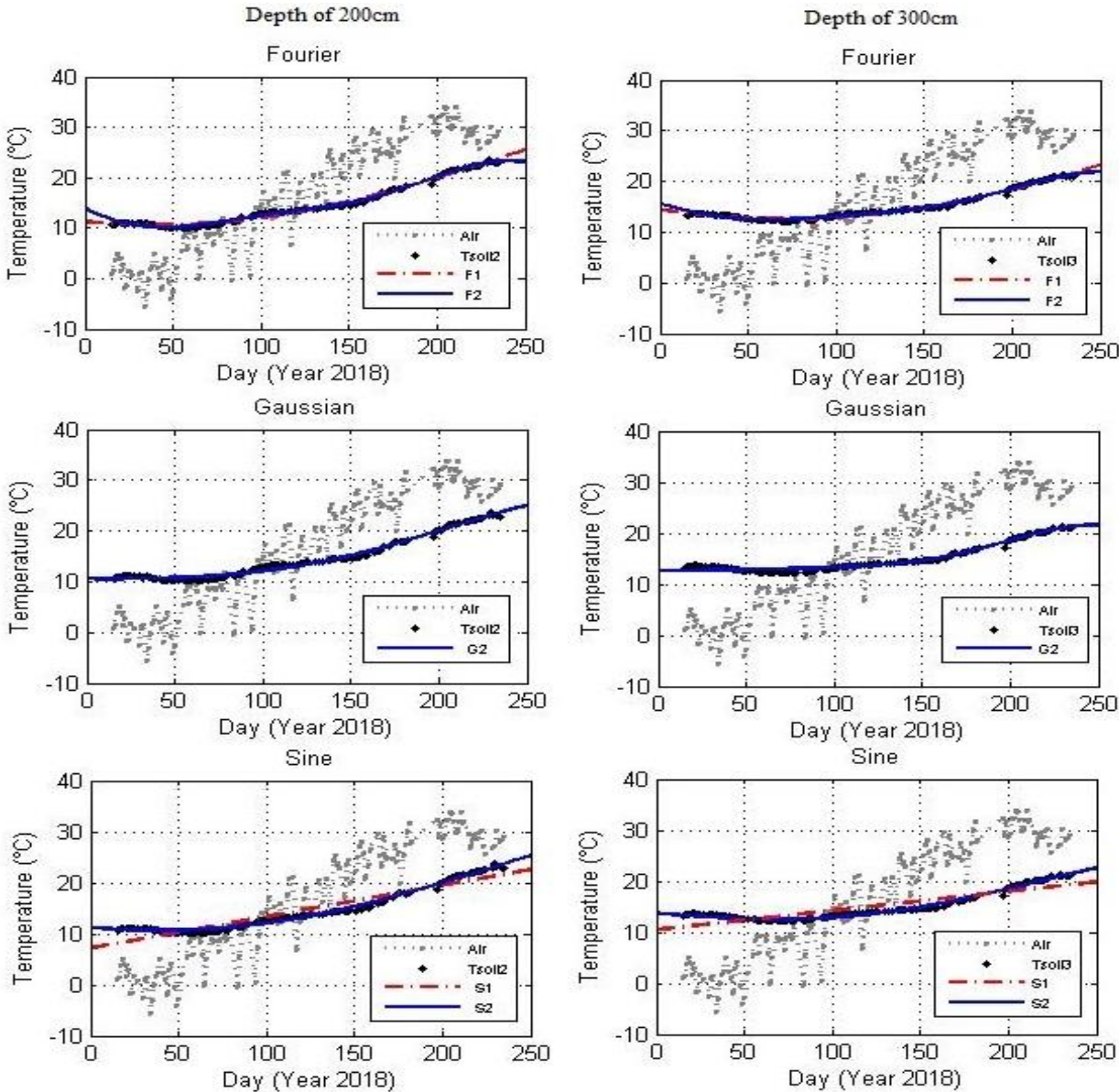

Figure 4. Empirical modeling of soil profile temperature fluctuation at the depths 200 and $300 \mathrm{~cm}$ 
TABLE 1. Summary of different empirical modeling results by Matlab

\begin{tabular}{|c|c|c|c|c|c|}
\hline $\begin{array}{l}\text { Soil depth } \\
\text { (cm) }\end{array}$ & Type of function & SSE $\left({ }^{\circ} \mathbf{C}\right)$ & $\mathbf{R}^{2}$ & RMSE $\left({ }^{\circ} \mathbf{C}\right)$ & Equation \\
\hline \multirow{6}{*}{30} & Fourier $(\mathrm{F} 1)$ & 440.98 & 0.963 & 1.74 & $f(t)=17.95-14.12 \cos (0.0105 t)+3.275 \sin (0.0105 t)$ \\
\hline & Fourier $(\mathrm{F} 2)$ & 140.6 & 0.988 & 0.988 & $\begin{array}{c}f(t)=17.13-4.252 \cos (0.023 t)-3.715 \sin (0.023 t)-3.715 \cos (0.045 t) \\
-2.051 \sin (0.045 t)\end{array}$ \\
\hline & Gaussian (G1) & 427.3 & 0.964 & 1.705 & $f(t)=31.3 \exp \left(-((t-257.1) / 172.6)^{2}\right)$ \\
\hline & Gaussian (G2) & 193.8 & 0.984 & 1.16 & $\begin{aligned} f(t)=12.83 \exp \left(-((t-100.1) / 69.83)^{2}\right) \\
+ \\
+29.79 \exp \left(-((t-212.9) / 65.73)^{2}\right)\end{aligned}$ \\
\hline & Sin $1(\mathrm{~S} 1)$ & 488.4 & 0.959 & 1.823 & $f(t)=222.3 \sin (0.0006 t+0.005)$ \\
\hline & Sin $2(\mathrm{~S} 2)$ & 349.5 & 0.971 & 1.558 & $f(t)=109 \sin (0.01577 t-0.71)+89.74 \sin (0.018 t+2.258)$ \\
\hline \multirow{6}{*}{100} & Fourier $(\mathrm{F} 1)$ & 118.8 & 0.981 & 0.902 & $f(t)=19.81-12.77 \cos (0.0091 t)+0.55 \sin (0.0091 t)$ \\
\hline & Fourier (F2) & 43.34 & 0.993 & 0.549 & $\begin{array}{c}f(t)=16.03-2.401 \cos (0.022 t)-7.775 \sin (0.022 t)-2.14 \cos (0.044 t) \\
-1.646 \sin (0.044 t)\end{array}$ \\
\hline & Gaussian (G1) & 128.4 & 0.98 & 0.935 & $f(t)=44.93 \exp \left(-((t-457.3) / 317.5)^{2}\right)$ \\
\hline & Gaussian (G2) & 88.6 & 0.986 & 0.784 & $f(t)=2.719 \exp \left(-((t-198.8) / 30.44)^{2}\right)+38.96 \exp \left(-((t-449.6) / 327.8)^{2}\right)$ \\
\hline & Sin $1(\mathrm{~S} 1)$ & 208 & 0.967 & 1.19 & $f(t)=1427 \sin (0.00007 t+0.00262)$ \\
\hline & $\operatorname{Sin} 2(\mathrm{~S} 2)$ & 118.6 & 0.981 & 0.907 & $f(t)=256.9 \sin (0.0106 t+0.084)+240.5 \sin (0.011 t+3.206)$ \\
\hline \multirow{6}{*}{200} & Fourier $(\mathrm{F} 1)$ & 31.68 & 0.988 & 0.456 & $f(t)=26.99-15.68 \cos (0.007 t)-4.69 \sin (0.007 t)$ \\
\hline & Fourier (F2) & 16.35 & 0.994 & 0.337 & $\begin{array}{c}f(t)=15.99-0.872 \cos (0.02 t)-5.97 \sin (0.02 t)-1.299 \cos (0.04 t) \\
-0.95 \sin (0.04 t)\end{array}$ \\
\hline & Gaussian (G1) & - & - & - & The Fit could not be computed due to error: Inf computed by model function. \\
\hline & Gaussian (G2) & 34.04 & 0.988 & 0.486 & $\begin{aligned} f(t)=19.39 \exp \left(-((t-305.2) / 144.9)^{2}\right) \\
\quad+5.14 \times 1014 \exp \left(-((t+6.965 \times 104) / 1.24 \times 104)^{2}\right)\end{aligned}$ \\
\hline & $\operatorname{Sin} 1(\mathrm{~S} 1)$ & 263.1 & 0.903 & 1.338 & $f(t)=653.5 \sin (9.42 t+0.011)$ \\
\hline & Sin $2(\mathrm{~S} 2)$ & 32.14 & 0.988 & 0.472 & $f(t)=599.4 \sin (0.00593 t+0.99)+587.5 \sin (0.0061 t+4.128)$ \\
\hline \multirow{6}{*}{300} & Fourier $(\mathrm{F} 1)$ & 13.7 & 0.988 & 0.3063 & $f(t)=31.09-16.63 \cos (0.0064 t)-8.086 \sin (0.0064 t)$ \\
\hline & Fourier (F2) & 9.762 & 0.992 & 0.2604 & $\begin{array}{c}f(t)=16.45+0.0078 \cos (0.012 t)-4.564 \sin (0.012 t)-0.826 \cos (0.024 t) \\
-0.562 \sin (0.024 t)\end{array}$ \\
\hline & Gaussian (G1) & - & - & - & The Fit could not be computed due to error:Inf computed by model function. \\
\hline & Gaussian (G2) & 27.72 & 0.976 & 0.439 & $\begin{aligned} f(t)=7.481 \exp \left(-((t-247) / 70.84)^{2}\right) & \\
& +2.34 \times 1013 \exp \left(-((t-1.214 \times 105) / 2.283 \times 104)^{2}\right)\end{aligned}$ \\
\hline & Sin $1(\mathrm{~S} 1)$ & 261.2 & 0.777 & 1.333 & $f(t)=495.1 \sin (0.000076 t+0.021)$ \\
\hline & $\operatorname{Sin} 2(\mathrm{~S} 2)$ & 16.93 & 0.985 & 0.3429 & $f(t)=70.37 \sin (0.007 t+0.616)+56.5 \sin (0.0086 t+3.639)$ \\
\hline
\end{tabular}

the soil temperature at this depth is lower than the temperature of the soil. The conclusion proves that this shallow depth geothermal energy capacity can be used in this location to meet the thermal requirements of a building such as a greenhouse which needs a lot of expenses to supply its thermal demands. It can also reduce the use of fossil fuels using heat exchangers based on shallow depth geothermal energy as a renewable energy resource. These results are consistent with the results obtained by previous researches $[15,22]$.

Since the results for the depths of 200 and $300 \mathrm{~cm}$ are closed, the depth of $200 \mathrm{~cm}$ can be used as an optimum depth to reduce the cost of the initial investment in drilling (Figure 4). By comparing the two modeling methods (Table 1), it can be concluded that both models suggest that a $300 \mathrm{~cm}$ depth is more capable of heating and cooling in winter and summer, respectively. However, the steps taken for the heat transfer model are quite time-consuming and cost-effective. As a result, empirical modeling can be used with acceptable accuracy as shown in Table 1.

\section{Heat transfer model}

The soil physical and thermal properties as well as some site meteorological parameters are briefly summarized in Table 2. According to Equation (7), the heat transfer model for the soil temperature at this location (Kouhsar, Alborz, Iran) was obtained as Equation (10) for all depths using the data taken from Alborz Meteorological Station from 2007 to 2017 as shown in Table 1.

$$
\begin{aligned}
& T_{(t, z)}=15.48+13.93 \cdot \exp \left[-z\left(\frac{\pi}{365 \alpha_{s}}\right)^{\frac{1}{2}}\right] \cos \left\{\frac{2 \pi}{365}[t-\right. \\
& \left.\left.192-\frac{z}{2}\left(\frac{365}{\pi \alpha_{s}}\right)^{\frac{1}{2}}\right]\right\}
\end{aligned}
$$

The results of temperature at each depth measured by the PT100 sensors along with predictions by the heat transfer model (explained in Equation (10)) are displayed in Figure 5. 
TABLE 2. Soil physical and thermal properties and meteorological parameters (at the temperature of $20^{\circ} \mathrm{C}$ )

\begin{tabular}{lc}
\hline Property & Field experiment \\
\hline Soil texture & Sandy loam \\
Soil dry density (Bulk density) & $1568.57\left(\mathrm{~kg} / \mathrm{m}^{3}\right)$ \\
Soil moisture content, $(\mathrm{w})$ & $12.48(\%)$ \\
Dry soil heat capacity, $\left(\mathrm{c}_{\mathrm{s}}\right)$ & $730\left(\mathrm{~J} / \mathrm{kg}^{\circ} \mathrm{C}\right)$ \\
Soil thermal diffusivity, $\left(\alpha_{\mathrm{s}}\right)$ & $0.07\left(\mathrm{~m}^{2} / \mathrm{day}\right)$ \\
Soil thermal conductivity, $\left(\mathrm{k}_{\mathrm{s}}\right)$ & $1.60\left(\mathrm{~W} / \mathrm{m}^{\circ} \mathrm{C}\right)$ \\
The mean ambient air temperature, $\left(\mathrm{T}_{\mathrm{am}}\right)$ & $15.48\left({ }^{\circ} \mathrm{C}\right)$ \\
$\begin{array}{l}\text { The annual amplitude of the ambient air } \\
\text { temperature, }\left(\mathrm{A}_{\mathrm{a}}\right)\end{array}$ & $13.93\left({ }^{\circ} \mathrm{C}\right)$ \\
$\begin{array}{l}\text { The phase constant }(\text { days }) \text { since the beginning } \\
\text { of the year of the highest Average ambient air } \\
\text { temperature, }\left(\mathrm{t}_{0}\right)\end{array}$ & $192(\mathrm{number})$ \\
\hline
\end{tabular}

As shown in Figure 5, the temperature of the soil at a depth of $30 \mathrm{~cm}$ is closed to the ambient air temperature (soil surface). As the depth increased from $30 \mathrm{~cm}$ to $300 \mathrm{~cm}$, the temperature difference of the soil surface and depth soil increased versus the soil surface temperature. However, in cold days (from January to March), the temperature of the earth at different depths was higher than the ambient air temperature while in the hot days (from June to September); the opposite of this case was observed. So, at a depth of 300 $\mathrm{cm}$ or more the depth soil temperature was lower in warm days and higher in cold days than the air temperature (soil surface). These results showed the capacity of an earth-air heat exchanger for cooling and heating proposes during warm as well as cold weather, respectively.

It was found that the RMSE values were 2.78, 2.06, 1.51 and $1.33^{\circ} \mathrm{C}$, at the depths of $30,100,200$ and $300 \mathrm{~cm}$, respectively. However, the results which obtained from this heat transfer model are in good accordance with the results reported by previous researches $[4,22,30]$.

Figure 6 shows the predicted soil temperature at various depths during the year 2018. It is observed that temperature fluctuations decrease with increasing soil depth. Figure 7 shows the range of soil amplitude fluctuations at different depths. It is observed that with increasing depth below the soil surface, the range of temperature fluctuations decreases, while the maximum and minimum soil surface temperatures during 2018 for the study area are 29.41 and $1.55^{\circ} \mathrm{C}$, respectively. The range of annual amplitude temperature changes at the soil surface in the area is $13.7^{\circ} \mathrm{C}$. As the soil depth increases, the amplitude of the oscillation decreases. When the depth reaches 0.3 , the amplitude of annual temperature changes at that depth reaches $12.33{ }^{\circ} \mathrm{C}$. The attenuation of the annual temperature wave is quite clear in Figure 8 . The depth of $3 \mathrm{~m}$ below the surface has a range of temperature fluctuations of $4.58{ }^{\circ} \mathrm{C}$, while at greater depths of 4, 5 and 6 , the temperature fluctuation ranges are 3.12, 2.17 and $1.53{ }^{\circ} \mathrm{C}$, respectively, which decrease the amplitude of soil temperature fluctuations by $1.46,0.95$ and $0.64{ }^{\circ} \mathrm{C}$, respectively, rather than the depth of $3 \mathrm{~m}$. Therefore, a depth of 3 meter can be an ideal depth for installing an air-to-ground heat exchanger pipe to utilize geothermal energy in the area in question $[22,31]$. In another study presented by Yassine et al. [32], a depth of $3 \mathrm{~m}$ was reported as the best depth for EAHE pipe application and geothermal energy utilization. Ascione et al. [31] reported the optimum depth for pipe operation was to be about $8 \mathrm{~m}$. They also reported depths of between 6 and $9 \mathrm{~m}$ as optimal depths due to minimum soil temperature fluctuations. Between the tests carried out by Ascione et al. [31], the heat exchange rate increased from the depth of $3 \mathrm{~m}$, this heat exchange slightly improved for the depth of $4 \mathrm{~m}$, which was not significant. They stated that if drilling costs were not limited, the depth selection would be more than $3 \mathrm{~m}$ in terms of heat exchange between the EAHE
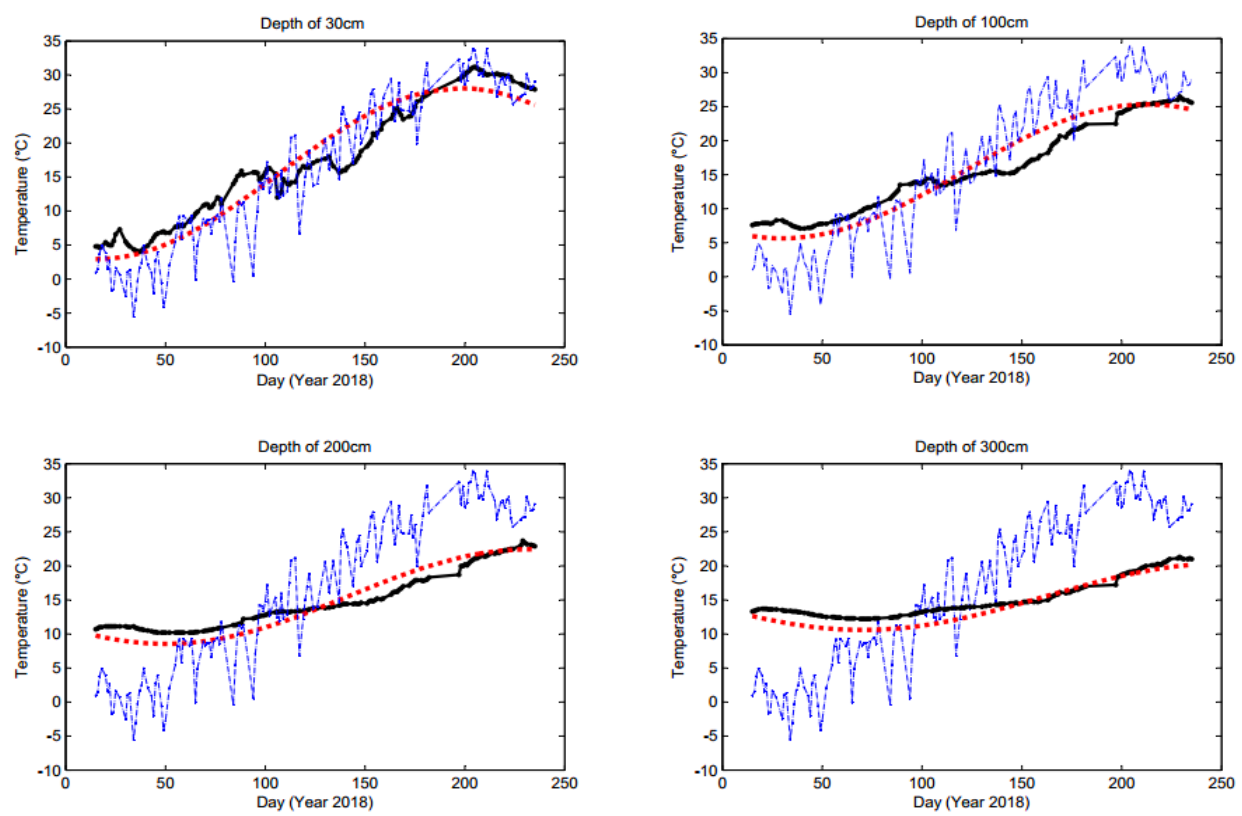

Figure 5. Daily-averaged soil temperature for various depths as a function of time along the 2018 year 
pipe and soil; otherwise a depth of $3 \mathrm{~m}$ could be optimum economically and in terms of heat exchange [31]. Gouda [22] reported the best depth of application of EAHE pipe system was the depth of $4 \mathrm{~m}$ that the soil temperature fluctuation range was $1.5^{\circ} \mathrm{C}$ and the amount of heat exchange between the soil and the pipe at the depth of $5 \mathrm{~m}$ did not improve significantly.

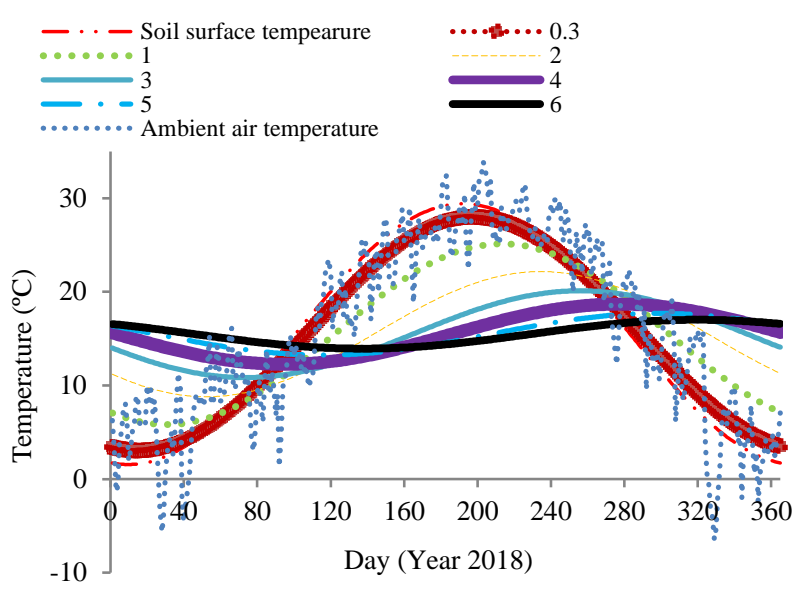

Figure 6. Daily predicted temperature of soil at different depth based on heat transfer model for year 2018

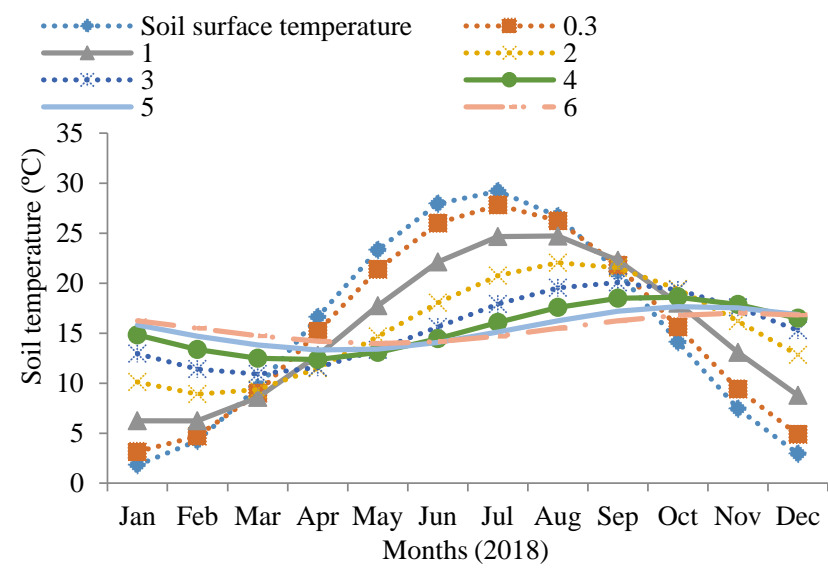

Figure 7. Monthly predicted soil temperature at various depths in 2018 based on heat transfer model

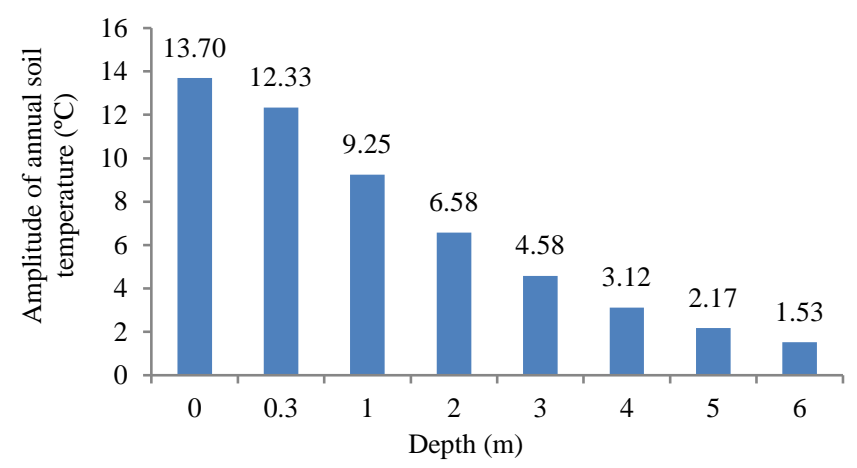

Figure 8. Amplitude of annual predicted soil temperature at various depths in 2018 based on heat transfer model (Zero depth = Soil surface temperature)

\section{CONCLUSION}

In this study, we are attempting to assess the possibility of using shallow depth geothermal energy to supply the thermal demands of agricultural buildings like greenhouses by modeling the thermal behavior of the Earth's temperature against the external air temperature in order to provide a way for predicting the temperature fluctuation for any depth and time in this position. However, two different modeling methods are presented as empirical and heat transfer models. The summary of results are as follows:

- Based on the results of empirical modeling for all four depths using the least squares regression method, the secondorder Fourier model introduces the best model describing soil thermal behavior at each depth (January 15 to September 1, 2018). This model shows the lowest SSE and RMSE versus the highest $\mathrm{R}^{2}$ at any of the specified depths.

- The heat transfer model of soil temperature showed the lowest and highest difference with soil surface temperature were obtained for the depth of $0.3 \mathrm{~m}$ and $3 \mathrm{~m}$, respectively. In the coldest days of the year (January to mid-March), the temperature in the depths of the earth is higher than the ambient air temperature. Also, on hot days of the year (midJune to late August), exactly the opposite is true for cold days. This demonstrates the potential of applying EAHE heat exchangers to meet the cooling and heating needs of greenhouse areas in the Kouhsar area.

- Given that a slight difference in the RMSE value for the two depths of 2 and $3 \mathrm{~m}$ were 1.51 and $1.33^{\circ} \mathrm{C}$ respectively, it can be said that the depth of $2 \mathrm{~m}$ can also be considered for geothermal energy use especially in areas with the problems of land drilling and its associated costs, pay less for depth selection to resolve such problems.

- Although, the results were in good agreement with those found in the literature but they were not as simple as the results obtained in this research by empirical model. Therefore, the heat transfer modeling method can be replaced by the empirical one with an acceptable accuracy.

- However, it may be necessary to have a secondary (supplementary) cooling and heating systems in summer as well as in winter depending on the location and specifications (thermal demand) of the desired region.

\section{REFERENCES}

1. Bisoniya, T.S., 2015. Design of earth-air heat exchanger system Geothermal Energy, 3(1), pp.1-10.

2. Sehli, A., Hasni, A. and Tamali, M., 2012. The potential of earth-air heat exchangers for low energy cooling of buildings in South Algeria. Energy Procedia, 18, pp.496-506.

3. Chel, A. and Kaushik, G., 2011. Renewable energy for sustainable agriculture. Agronomy for Sustainable Development, 31(1), pp.91118 .

4. Vaz, J., Sattler, M.A., Brum, R.D.S., dos Santos, E.D. and Isoldi, L.A., 2014. An experimental study on the use of Earth-Air Heat Exchangers (EAHE). Energy and Buildings, 72, pp.122-131.

5. Ganguly, A. and Ghosh, S., 2011. A review of ventilation and cooling technologies in agricultural greenhouse application. Iranica Journal of Energy \& Environment, 2(1), pp.32-46. 
6. Sethi, V.P. and Sharma, S.K., 2008. Survey and evaluation of heating technologies for worldwide agricultural greenhouse applications. Solar Energy, 82(9), pp.832-859.

7. Vourdoubas, J., 2015. Possibilities of Using Renewable Energy Sources for Covering all the Energy Needs of Agricultural Greenhouses Journal of Agriculture and Life Sciences, 2, pp.111-118.

8. Vourdoubas, J., 2015. Overview of heating greenhouses with renewable energy sources a case study in Crete-Greece. Journal of Agriculture and Environmental Sciences, 4(1), pp.70-76.

9. Do, S.L. and Haberl, J., 2018, February. Development of a groundcoupled heat pump system simulation model using g-function approximation for a residential code-compliant tool. Building Simulation, 11(1), pp.51-66.

10. Ramos, R., Aresti, L., Christodoulides, P., Vieira, A. and Florides, G., 2018, September. Assessment and comparison of soil thermal characteristics by laboratory measurements. In International Symposium on Energy Geotechnics, Springer, Cham, pp.155-162.

11. Qu, S., Han, J., Sun, Z., Yin, R., Ji, R. and Chai, C., 2019, August. Study of operational strategies for a hybrid solar-geothermal heat pump system. Building Simulation, 12(4), pp.697-710.

12. Bisoniya, T.S., Kumar, A. and Baredar, P., 2014. Parametric analysis of Earth-air heat exchanger system based on CFD modelling. International Journal of Power and Renewable Energy Systems, 1 , pp.36-46.

13. Vieira, A., M., Alberdi-Pagola, P., Christodoulides, S., Javed, F., Loveridge, F., Nguyen, F., Cecinato, J., Maranha, G., Florides, I., Prodan and G.V., Lysebetten, 2017. Characterisation of ground thermal and thermo-heat transfer behaviour for shallow geothermal energy applications. Energies, 10(2044), pp.1-53.

14. Bansal, V., Misra, R., Agrawal, G.D. and Mathur, J., 2009. Performance analysis of earth-pipe-air heat exchanger for winter heating. Energy and Buildings, 41(11), pp.1151-1154.

15. Bansal, V., Misra, R., Agrawal, G.D. and Mathur, J., 2010 Performance analysis of earth-pipe-air heat exchanger for summer cooling. Energy and Buildings, 42(5), pp.645-648

16. Hatraf, N., Chabane, F., Brima, A., Moummi, N. and Moummi, A., 2014. Parametric study of to design an earth to air heat exchanger with experimental validation. Engineering Journal, 18(2), pp.41-54.

17. Luo, Z., Wang, Y., Zhou, S. and Wu, X., 2015. Simulation and prediction of conditions for effective development of shallow geothermal energy. Applied Thermal Engineering, 91, pp.370-376.

18. ASHRAE, 2007. Handbook: Heating, ventilating, and air-conditioning applications. Atlanta (GA).

19. Derbel, H.B.J. and Kanoun, O., 2010. Investigation of the ground thermal potential in tunisia focused towards heating and cooling applications. Applied Thermal Engineering, 30(10), pp.1091-1100.

20. Chow, T.T., Long, H., Mok, H.Y. and Li, K.W., 2011. Estimation of soil temperature profile in Hong Kong from climatic variables. Energy and Buildings, 43(12), pp.3568-3575.

21. Bansal, V., Misra, R., Agrawal, G.D. and Mathur, J., 2012. Performance evaluation and economic analysis of integrated earth-airtunnel heat exchanger-evaporative cooling system. Energy and Buildings, 55, pp.102-108.

22. Gouda, A., 2010. Using of geothermal energy in heating and cooling of agricultural structures, PhD Dissertation, Benha University, Egypt.

23. Mihalakakou, G., 2002. On estimating soil surface temperature profiles. Energy and Buildings, 34(3), pp.251-259.

24. Ozgener, L., 2011. A review on the experimental and analytical analysis of earth to air heat exchanger (EAHE) systems in Turkey. Renewable and Sustainable Energy Reviews, 15(9), pp.4483-4490.
25. Ozgener, O. and Ozgener, L., 2010. Exergoeconomic analysis of an underground air tunnel system for greenhouse cooling system. International Journal Of Refrigeration, 33(5), pp.995-1005.

26. Ozgener, O. and Ozgener, L., 2011. Determining the optimal design of a closed loop earth to air heat exchanger for greenhouse heating by using exergoeconomics. Energy and Buildings, 43(4), pp.960-965.

27. Yao, W., Li, Z., Wang, Y., Jiang, F. and Hu, L., 2014. Evaluation of global solar radiation models for Shanghai, China. Energy conversión and management, 84 , pp.597-612.

28. Sharan, G. and Jadhav, R., 2002. Soil temperature regime at Ahmedabad. Journal of Agricultural Engineering, 39(1), pp.27-32.

29. Kersten, M.S., 1949. Laboratory research for the determination of the thermal properties of soils. Research Laboratory Investigations, Engineering Experiment Station. University of Minnesota, Minneapolis, Technical Report, 23.

30. Al-Ajmi, F., Loveday, D.L. and Hanby, V.I., 2006. The cooling potential of earth-air heat exchangers for domestic buildings in a desert climate. Building and Environment, 41(3), pp.235-244.

31. Ascione, F., Bellia, L. and Minichiello, F., 2011. Earth-to-air hea exchangers for Italian climates. Renewable Energy, 36(8), pp.21772188.

32. Yassine, B., Ghali, K., Ghaddar, N., Chehab, G. and Srour, I., 2014 Effectiveness of the earth tube heat exchanger system coupled to a space model in achieving thermal comfort in rural areas. International Journal of Sustainable Energy, 33(3), pp.567-586

\section{APPENDIX A}

\begin{tabular}{lc}
\hline & List of Symbols \\
\hline $\mathrm{T}$ & Temperature $\left({ }^{\circ} \mathrm{C}\right)$ \\
\hline$T_{\text {mean }}$ & The mean soil surface temperature $\left({ }^{\circ} \mathrm{C}\right)$ \\
\hline$A_{s}$ & The annual amplitude of the soil surface temperature $\left({ }^{\circ} \mathrm{C}\right)$ \\
\hline$t$ & The time in year (days) from starting date of year (number) \\
\hline$t_{0}$ & $\begin{array}{r}\text { The phase constant (days) since the beginning of the year } \\
\text { of the maximum average ground surface temperature }\end{array}$ \\
\hline$\alpha_{\mathrm{s}}$ & Thumber) \\
\hline$T_{m a}$ & The mean ambient air temperature $\left({ }^{\circ} \mathrm{C}\right)$ \\
\hline $\mathrm{A}_{\mathrm{a}}$ & The annual amplitude of the ambient air temperature $\left({ }^{\circ} \mathrm{C}\right)$ \\
\hline$c_{w}$ & specific heat of water which is equal to $4.18 \mathrm{~kJ} / \mathrm{kg}^{\circ} \mathrm{C}$ \\
\hline$c_{s}$ & The specific heat of dry soil $\left(\mathrm{kJ} / \mathrm{kg}^{\circ} \mathrm{C}\right)$ \\
\hline$\rho_{\mathrm{s}}$ & The soil dry bulk density $\left(\mathrm{kg} / \mathrm{m}^{3)}\right.$ \\
\hline $\mathrm{w}$ & The moisture content of soil, $\%(\mathrm{dry} \mathrm{basis)}$ \\
\hline$k_{s}$ & Calculated value \\
\hline $\mathrm{m}_{\mathrm{i}}$ & Measured value \\
\hline
\end{tabular}




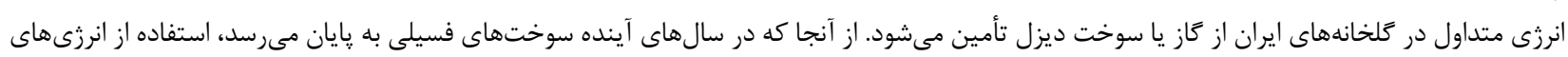

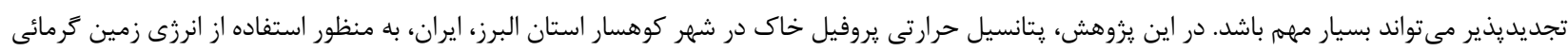

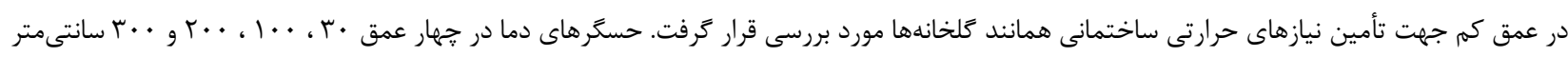

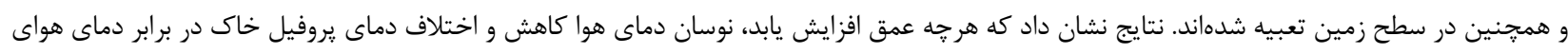

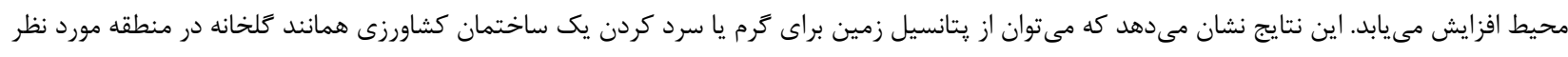

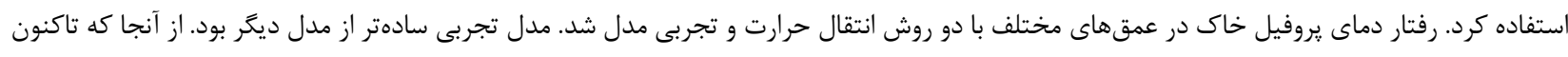

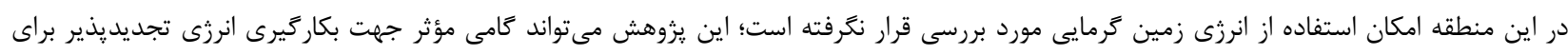
سازمهاى كشاورزى هماند كلخانهها باشد. 